\title{
INVESTIGANDO O ENSINO DE TRIGONOMETRIA ATRAVÉS DA INTERDISCIPLINARIDADE COM UM SIMULADOR DA PLATAFORMA PhET
}

\author{
INVESTIGATING THE TEACHING OF TRIGONOMETRY THROUGH \\ INTERDISCIPLINARITY WHIT A SIMULATOR OF THE PHET PLATFORM
}

\author{
Patrícia de Souza Moura ${ }^{1}$ \\ ORCID iD: $\underline{0000-0002-9069-8320}$
}

Maria do Socorro Ferreira Ramos ${ }^{2}$

ORCID iD: 0000-0001-6943-6732

Otávio Paulino Lavor ${ }^{3}$

ORCID iD: 0000-0001-5237-3392

\begin{abstract}
RESUMO
O conteúdo de trigonometria tem diversas aplicações dentro da Matemática e em outras áreas, como a Física, de forma que o seu conhecimento irá auxiliar na compreensão de diversos fenômenos. Nesse sentido, pode-se pensar em apresentar este conteúdo de forma interdisciplinar, através de tecnologias de ensino para verificar a contribuição para o ensino e aprendizagem. Dessa forma, este trabalho apresenta a aplicação de uma Sequência de Ensino Investigativa na exposição da trigonometria e suas aplicações, buscando a interdisciplinaridade através do simulador Lançamento de projéteis da plataforma PhET. A investigação mostrou que houve uma interação e motivação por meio dos estudantes com relação ao conteúdo e a forma que foi aplicado, mostrando uma estreita relação entre a trigonometria e o lançamento de projéteis. Os comentários finais apontaram que o público aprovou a utilização da plataforma PhET numa perspectiva interdisciplinar e que o conteúdo de trigonometria quando ensinado de forma aplicada em outro conteúdo possibilita uma melhor aprendizagem.
\end{abstract}

Palavras-chave: Sequência de Ensino Investigativa. Lançamento de Projéteis. Interação.

\begin{abstract}
Content of trigonometry has several applications within Mathematics and in other areas, such as Physics, so that your knowledge will help in understanding various phenomena. In this sense, one can think about presenting this content in an interdisciplinary way, through teaching technologies to verify the contribution to teaching and learning. Thus, this work presents the application of an Investigative Teaching Sequence in the exposure of trigonometry and its applications, seeking interdisciplinarity

\footnotetext{
${ }^{1}$ Mestranda do Programa de Pós-Graduação em Ensino (PPGE) da Universidade do Estado do Rio Grande do Norte (UERN), Pau dos Ferros, Rio Grande do Norte, Brasil. Endereço para correspondência: BR-405, Km 3, Arizona, Pau dos Ferros -RN, Brasil, CEP:59900-000. E-mail: patryciacedro@ gmail.com.

${ }^{2}$ Mestranda do Programa de Pós-Graduação em Ensino (PPGE) da Universidade do Estado do Rio Grande do Norte (UERN), Pau dos Ferros, Rio Grande do Norte, Brasil. Endereço para correspondência: BR-405, Km 3, Arizona, Pau dos Ferros -RN, Brasil, CEP:59900-000. E-mail: mariasframos@ gmail.com.

${ }^{3}$ Doutorado em Engenharia Elétrica pela Universidade Federal do Rio Grande do Norte (UFRN). Professor Adjunto na Universidade Federal Rural do Semi-árido (UFERSA), Pau dos Ferros, Rio Grande do Norte, Brasil. Endereço para correspondência: BR-226, Km 405, Pau dos Ferros -RN, Brasil, CEP: 59900-000. E-mail: otavio.lavor@ufersa.edu.br.
} 
through projectile launch simulator of the PhET platform. The investigation showed that there was an interaction and motivation through the students regarding the content and the form that was applied, showing a close relation ship between trigonometry and the launching of projectiles. The final comments pointed out that the public approved the use of the PhET platform in an interdisciplinary perspective and that the content of trigonometry when taught in an applied way in other content enables better learning.

Keywords/Palabras clave: Investigative Teaching Sequence. Launch of Projectile. Interaction.

\section{INTRODUÇÃO}

O ensino de Matemática contempla nos dias atuais muitas funções importantes dentro da educação e ensinar Matemática vai além de expor fórmulas e repassar questões. Reisl et al (2019) afirma que o ensino dos conteúdos de matemática passa por diversas críticas, resultando na insatisfação de discentes e docentes, pois os conteúdos ministrados muitas vezes parecem inacessíveis e/ou difíceis de compreender e ensinar. A cada dia, é exigido do professor, metodologias de ensino que possam contemplar a prática, seja utilizando recursos tecnológicos ou materiais concretos e, assim, possa colaborar para que os discentes consigam ver a matemática de uma outra forma, não como uma disciplina difícil, mas como acessível, e que possibilita diversos caminhos de compreensão.

Quando resolve-se falar sobre ensino, isso remete ao professor demonstrar essa importância em analisar sua prática pedagógica, como também o público que está direcionando. Para Dalarosa (2008, p.7), refletir sobre a pratica docente, deve também remeter a esta pergunta: "a serviço de quem e de que eu estou quando educo?". O autor é feliz em sua colocação, e remete também que esse questionamento não é o fim, mas um início e uma constante, quando demonstra a necessidade de uma análise e reflexão de requisitos que serão necessários a serem aplicados, para que a prática docente seja significativa, compreensiva e que possa levar o discente a uma interação, não por obrigação, mas por vontade própria.

Esse dinamismo durante a aula, que proporciona ao discente compreender de forma visual a parte prática do conteúdo exposto demonstra uma importância, pois existe uma diferença significativa entre expor, dialogando um fato do cotidiano e mostrar de forma visual esta prática. Dessa forma, a prática docente deve ser pensada com cautela e planejamento, pois diversas informações e alguns achismo precisam ser desconstruídos.

Franco (2012) expõe que a prática pedagógica quando integrada a reflexão contínua e coletiva e assegurando a sua proposta é contemplada para todos, será pedagógica, à medida que 
a busca pelas construções de suas práticas e que possam garantir que a proposta de ensino corrobore com suas intencionalidades para que sejam realizadas.

É necessário um planejamento e estratégias que possam contribuir para que as práticas pedagógicas tenham finalidade, mas é necessário compreender, assim como cita Franco (2012), que o educador sozinho não consegue atuar, pois precisa de apoio institucional e condições favoráveis que apõem sua prática e valorize seus saberes, como também, condições que contribuam para a organização de intencionalidades coletivas, que possam refletir sobre intencionalidade da escola e incentive suas inovações e reflexões.

Essas contribuições coletivas refletem também em como o ensino de matemática encontra-se presente em diversas disciplinas afins e não afins, compreender sua aplicação em diversos contextos e demostrar isso através do ensino, torna-se de fundamental importância, determina que uma ciência não necessariamente deve andar sozinha, mas contribuir efetivamente para as demais, e vice-versa. Demonstrar ao estudante essa relação, favorece para que o mesmo consiga entender que a Matemática não é uma ciência isolada.

Assim, a interdisciplinaridade é um conceito que compreende em unir duas ou mais disciplinas com uma mesma finalidade, relacionando-as de forma complementar. Loureiro et al. (2019), afirma que a ideia de interdisciplinaridade é empregada para determinar dois aspectos diferentes: uma delas funciona como uma super disciplina, que pode ser compreendido como um enfoque permanente de objetos que lhe é dedicada, a outra funciona como uma aplicação importante de conceitos de distintas disciplinas e que favorece na resolução de problemas concretos.

Souza e Fazenda (2017) destacam que por meio da perspectiva de interdisciplinaridade, sendo possível compreender o conhecimento como algo não fragmentado, podendo ocorrer a união com outros conhecimentos, corroborando para relações de proximidade e possibilitando que os sujeitos, os quais interagem com o conhecimento, possam ser capazes de questionar os objetos que serão encontrados.

Sendo assim, diversas metodologias são empregadas no ensino de matemática e se apresentam em diversos aspectos, mesmo que muitas vezes sejam trabalhadas com as mesmas disciplinas e conteúdo, mas a abordagem ocorre de forma distinta.

Em relação à trigonometria, Lopes (2011) utilizou o software GeoGebra como recurso tecnológico, enquanto que Oliveira (2006) utilizou uma Engenharia Didática, para tratar sobre as dificuldades encontradas no processo de ensino e aprendizagem deste conteúdo. Dionizio e Brandt (2011) utilizaram Registros de Representação Semiótica para identificar as dificuldades encontras pelos discentes do ensino médio, através de uma abordagem qualitativa em que 
utilizaram a aplicação de um questionário envolvendo o conteúdo proposto. Já Oliveira e Fernandes (2010) utilizaram diversas tecnologias digitais como metodologias para o ensino e aprendizagem.

Nesse sentido, este trabalho consiste em uma proposta interdisciplinar que utiliza uma Sequência de Ensino Investigativo (SEI), com o propósito de envolver a Matemática e a Física, através dos conteúdos de Trigonometria e Lançamento de projéteis, utilizando o simulador lançamento de projéteis da plataforma PhET, como recurso tecnológico.

\section{REFERÊNCIAL TEÓRICO}

\subsection{Interdisciplinaridade}

A interdisciplinaridade quando relacionada ao ensino de Matemática, pode compreender e se apresentar em diversas áreas, como exatas ou naturais. As mesmas, podem se relacionar em diversos contextos de aplicações e levam ao discente a envolver os aspectos de como a matemática pode estar inserida em outra disciplina, e como ocorre esta relação interdisciplinar. Santos (2008,) compreende a interdisciplinaridade através da ciência pós-moderna, onde acredita que não há conhecimento, em si mesmo, racional; só a configuração de todas as ciências é racional. Assim, tenta dialogar com outras formas de conhecimento deixando aprofundar-se por elas.

\footnotetext{
A interdisciplinaridade tem função instrumental e deve ser entendida a partir de uma abordagem relacional, onde são estabelecidas interconexões entre os conhecimentos, porém respeitando as especificidades de cada disciplina. Nos currículos moldados da escola, a interdisciplinaridade é citada de forma sucinta, como uma estratégia para alcançar os objetivos defendidos pela escola. (GONÇALVES; BONI; GOMES; 2019, p. 12).
}

Correia (2019) determina que a interdisciplinaridade é uma ação teórico- metodológica comum que envolvem toda as áreas, sendo assim, o problema resolvido de forma articulada e integrada, possibilitando que o interesse de cada disciplina seja mantido. Loureiro et al. (2019) concorda com essa indagação ao afirmar que interdisciplinaridade é uma perspectiva epistemológica pós-moderna, surgindo pela compreensão de que as disciplinas mesmo que cientificas, quando trabalhadas solitariamente, normalmente podem se apresentar restritas e parciais.

Dessa forma, ao se deparar com o ensino de Matemática e de Física, se percebe a dificuldades e resistências encontradas pelos discentes, que costumam caracterizar, ambas as 
disciplinas, como difíceis de compreensão. Nunes et al. (2019) cita que o ensino de Física, assim como a Matemática, também é considerado uma disciplina difícil compreensão e execução, pois os discentes apresentam dificuldades na aprendizagem quanto a relação dos conceitos e suas aplicações em seu cotidiano, tornando-se uma disciplina "chata", retratando um senso comum.

O senso comum é interdisciplinar e imetódico; não resulta de uma prática especificamente orientar para o produzir; reproduz-se espontaneamente no suceder quotidiano da vida. $\mathrm{O}$ senso comum aceita o que existe tal como existe; privilegia a acção que não produza rupturas significativas no real. Por último, o senso comum é histórico e metafórico; não ensina, persuade." (SANTOS, 2008, p. 90).

Dessa forma, a interdisciplinaridade aliada a recursos tecnológicos pode colaborar com a mudanças desses conceitos já escancarados há muito tempo, e assim possa levar ao aluno a uma abordagem mais significativa, que contribua para sua análise, aplicação e compreensão mais ampla da matemática e de seu contexto relacional com a física. Santos et al. (2019) cita que a inter-relação entre a matemática e a física no ensino, apresenta-se como ferramenta, contendo importantes conceitos, em que se pode relacioná-los e assim, corroborando para um ensino e aprendizagem significativa para o discente.

\subsection{Tecnologias no ensino e aprendizagem}

O uso de tecnologias no ensino de matemática compreende de um fator muito importante para o processo de ensino e aprendizagem, pois proporciona que a prática seja integrada a teoria e que o discente possa compreender pela visualização do recurso tecnológico a aplicação do conteúdo específico.

Sob esse ponto de vista a tecnologia pode transformar-se em um recurso essencial à melhoria do ensino e da aprendizagem de conteúdos matemáticos uma vez que pode proporcionar uma maior autonomia ao aluno no processo de construção do conhecimento. Assim, ela pode potencializar a aprendizagem uma vez que permite momentos de construção de conhecimentos. (BRITO; MOITA; LOPES, 2018, p. 9).

Essa autonomia dada ao discente através do uso das tecnológicas compreende e contribui para um desenvolvimento cognitivo e no seu processo de aprendizagem, pois o discente, pode entender, além da teoria o que a disciplina aborda. Quando a tecnologia é aliada ao ensino, e a interdisciplinaridade, pode favorecer no processo desse desenvolvimento, sendo possível, através dela, demonstrar a relação entre teoria e prática e até onde uma disciplina se relaciona a outra. Entre os mais diversos recursos tecnológicos relacionados ao ensino, os 
simuladores apresentam com grande valia, quando proporciona utilizar contextos atuais nas abordagens das disciplinas correspondentes.

Zara (2011) cita que a informática educativa proporciona diversas formas de utiliza-la no ensino e nas ciências, os softwares de simulação têm uma finalidade importante, pois apresentam-se como laboratórios virtuais e podem contribuir de forma significante na sala de aula.

Dentre as práticas pedagógicas que investigam melhorias no ensino e aprendizagem na matemática, pode-se citar Feitosa, Aquino e Lavor (2020), que utilizam o GeoGebra para o ensino de retas e planos e verificam que os alunos que participaram de aulas mediadas pelo aplicativo, tiveram resultados mais satisfatórios ao serem submetidos a um teste de questões subjetivas. Cavalcante e Sales (2020) utilizam recursos de simulações da plataforma PhET para o ensino de mecânica Newtoniana e também concluem que os resultados são melhores com o uso da tecnologia.

Simulações da plataforma PhET também foram usadas por Feitosa e Lavor (2020) no ensino de circuitos elétricos e percebem que os alunos se sentiram mais motivados a participarem de forma ativa na construção do conhecimento. Fatos como esse mostram que as plataformas de simulações auxiliam criando um ambiente favorável a aprendizagem.

No caso do PhET, trata-se de uma plataforma que disponibiliza simuladores virtuais nas áreas de Matemática, Física, Química e Biologia, e que permite também acontecer uma interdisciplinaridade entre a utilização desses simuladores em relação às disciplinas. O PhET é livre e gratuito e deve ser utilizado com acesso à internet. Os simuladores permitem uma visualização do conteúdo e proporcionam, através de situações contextualizada ao cotidiano, uma melhor aplicação e visualização.

\subsection{Sequência de Ensino Investigativa}

As Sequencias de Ensino Investigativas (SEI) foram propostas por Carvalho (2013, p.7), e destaca que são:

Sequências de atividades (aulas) abrangendo um tópico do programa escolar em que cada uma das atividades é planejada, sob o ponto de vista do material e das interações didáticas, visando proporcionar aos alunos: condições de trazer seus conhecimentos prévios para iniciarem os novos, terem ideias próprias e poder discuti-las com seus colegas e com o professor passando do conhecimento espontâneo ao científico e tendo condições de entenderem conhecimentos já estruturados por gerações anteriores. 
Como exemplos de utilização da SEI no contexto escolar, pode-se citar Feitosa e Lavor (2020) utiliza as Sequencias de Ensino Investigativo para o ensino de circuitos elétricos com auxílio de um simulador, em que os estudantes poderiam interagir com o simulador e construir os circuitos propostos na aula. Enquanto, Moura e Silva (2019) utiliza a SEI no estudo de Empuxo no ensino de Física, a fim de construir um produto educacional que venha a colaborar no ensino e aprendizagem através da investigação.

\begin{abstract}
Ao analisar o papel e função dos problemas abordados em SEI, parte-se do pressuposto de que há uma certa modificação na função exercida por eles. Entende-se que a função dos problemas didáticos pode sofrer alterações a depender da posição que ocupam na sequência de ensino e essa posição envolve tanto a análise da estruturação ou planejamento das SEI, quanto do desenvolvimento ou implementação da mesma em sala de aula. (SALINO; SASSERON; 2018, p. 6).
\end{abstract}

Lima (2015) utilizou a SEI em aulas de ciências do ensino fundamental II, fundamentando e refletindo aprendizagens de conceitos e procedimentos. Nascimento (2016) utilizou a SEI para a construção de materiais educacionais para serem utilizadas no ensino fundamental. Santos (2016) empregou as Sequências de Ensino Investigativo com o objetivo de promover a Alfabetização Científica em séries iniciais do ensino fundamental. Enquanto, Bellucco (2014) para contribuir com a valorização do ensino de física, utilizou a SEI como proposta de desenvolvimento de situações argumentativas que possam contribuir para o processo de aprendizagem.

Assim, as SEI compreendem uma sequência planejada de etapas, compreendido de uma análise de como o conteúdo e os recursos devem ser realizados mediante a necessidade da turma. Essas etapas não são feitas de forma aleatória, pois compreende de processos integrados, em que Azevêdo e Fireman (2017), incluem que a atividade investigativa necessita de direcionamento eficiente do tema abordado, tornando a sala de aula um local investigativo, sendo assim, é necessário e importante que o docente também se aproprie destas estratégias.

\title{
3 METODOLOGIA
}

A pesquisa foi realiza no mês de maio de 2020, com os estudantes na $3^{\mathrm{a}}$ série do ensino médio de uma escola pública localizada na região Centro Sul do Estado do Ceará. Participaram 16 (dezesseis) alunos, com o intuito de avaliarem a aplicação do conteúdo de Trigonometria de forma interdisciplinar com Lançamentos de Projeteis, utilizando a SEI.

No primeiro momento, ocorreu a apresentação do conteúdo de trigonometria, relacionando com a aplicação em outras áreas do conhecimento, bem como dentro da própria 
matemática. Por conseguinte, foi apresentado o simulador de Lançamento de Projeteis da plataforma PhET, em que a tela inicial apresenta a imagem do canhão, determinada por um ângulo, que está relacionada a uma distância onde encontra-se o alvo. O objetivo é que o estudante consiga, utilizando as informações importantes do simulador, atirar a bala para acertar o alvo. A Figura 1 mostra a interface deste simulador.

Figura 1: Interfase do simulador Movimento de Projeteis da plataforma PhET

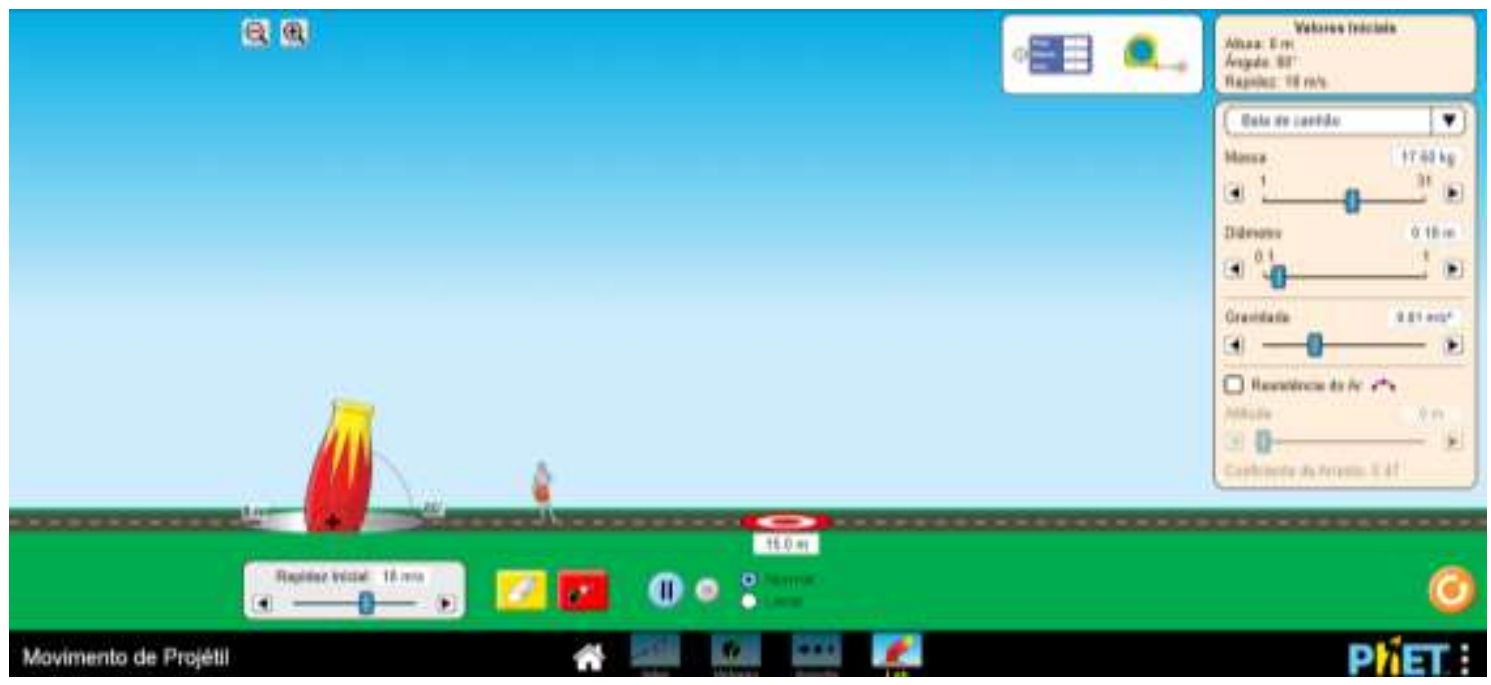

No segundo momento, foram utilizados exemplos aleatórios no simulador, com o objetivo de levar o discente compreender a necessidade de um cálculo exato, para que se alcance o objetivo final e que de forma aleatório as chances seriam menores da bala do canhão acertar o alvo.

No terceiro momento, após a demonstração, foram realizados exemplos práticos que utilizavam a equação de lançamento de projeteis e que posteriormente as respostas encontradas eram aplicadas no simulador, levando o aluno a compreender que, por meio do cálculo exato, levava a bala do canhão a acertar o alvo, mesmo que de uma questão para outra, os contextos sejam mudados como a velocidade, distância do alvo e a inclinação do canhão, a aplicação da equação funcionaria para todos os contextos.

Após isso, os discentes foram convidados a responderem a atividade de fixação contendo quatro questões subjetivas, em que foram solicitados aos discentes que apresentassem na resolução, o cálculo da questão, utilizando a equação de lançamento de projéteis e posteriormente executassem a aplicação no simulador da plataforma PhET.

A avaliação da aprendizagem foi realizada verificando a participação, motivação e interação dos discentes durante a aula como também, a resolução da atividade final. Posteriormente, os discentes responderam um questionário de satisfação, contendo 5 (cinco) 
questões objetivas que buscaram compreender o nível de contentamento dos discentes quanto a esta aplicação interdisciplinar utilizando o simulador de lançamento de projéteis.

\section{ANÁLISES E RESULTADOS}

Após a apresentação dos conteúdos de trigonometria, buscou-se demonstrar a obtenção da equação de lançamento de projéteis, mas, para que isso acontecesse, foram necessárias recorrer outras disciplinas e conteúdo. Na matemática, com a trigonometria, foi utilizado as definições de seno e cosseno, com a álgebra na utilização de sistemas de equações, e na geometria analítica quando relacionado o estudo de vetores. Na Física, foi abordado conceitos mecânicos como Movimento Retilíneo Uniforme e Uniformemente Variado.

Inicialmente, o simulador de lançamento de projéteis foi apresentado através de exemplos aleatórios no momento da aula. Após isso, foi iniciada a demonstração para encontrar a equação de lançamentos de projeteis, em que foi mostrado a relação de seno e cosseno em relação ao plano existente, mesmo que seja apresentada de forma implícita no simulador. A figura 2 mostra a decomposição de velocidades no plano cartesiano.

Figura 2: Decomposição do vetor velocidade.

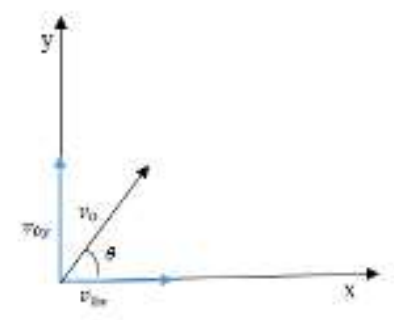

Neste momento, foram apresentados conceitos de Movimento Retilíneo Uniforme que estava relacionado ao movimento na direção $x$ no lançamento do projétil e determinado pela equação

$$
x(t)=x_{0}+v_{0 x} t
$$

em que $x_{0}=0$, uma vez que o movimento parte da origem e usando a definição de cosseno, tem-se $v_{0 x}=v_{0} \cos \theta$.

Na direção $y$, tem-se o Movimento Retilíneo Uniformemente Variado em que a aceleração é dada pela gravidade que tem valor numérico de $g=9,81 \mathrm{~m} / \mathrm{s}$. A equação do movimento é

$$
y(t)=y_{0}+v_{0 y} t+\frac{1}{2} g t^{2}
$$


em que $y_{0}=0$, uma vez que o movimento parte da origem e usando a definição de seno, temse $v_{0 y}=v_{0} \operatorname{sen} \theta$.

As equações 1 e 2 fornecem o movimento do projétil em qualquer instante de tempo $t$. Assim, para que o projétil alcance o alvo que está sobre o eixo $x$, é necessário que o valor de $y$ seja igual a zero, que acontece em $t_{1}=0 \mathrm{e}$

$$
t_{2}=\frac{2 v_{0} \operatorname{sen} \theta}{g}
$$

$\mathrm{O}$ tempo $t_{1}$ corresponde à origem e $t_{2}$ corresponde à posição que está o alvo. Então substituindo a equação 3 na equação 1, tem-se que

$$
x(t)=\frac{2 v_{0}^{2} \cos \theta \operatorname{sen} \theta}{g}
$$

que fornece o alcance em função do ângulo e da velocidade do lançamento. Então, verificando a posição do alvo e escolhendo o ângulo, pode-se determinar a velocidade de lançamento. A Figura 3 mostra o alvo sendo alcançado no simulador, em que tem-se um alcance de $18 \mathrm{~m}$ e foi escolhido no ângulo de $45^{\circ}$ e a velocidade de $13 \mathrm{~m} / \mathrm{s}$ foi determinado pela equação 4 .

Figura 3: Lançamento de projetil de um exemplo prático

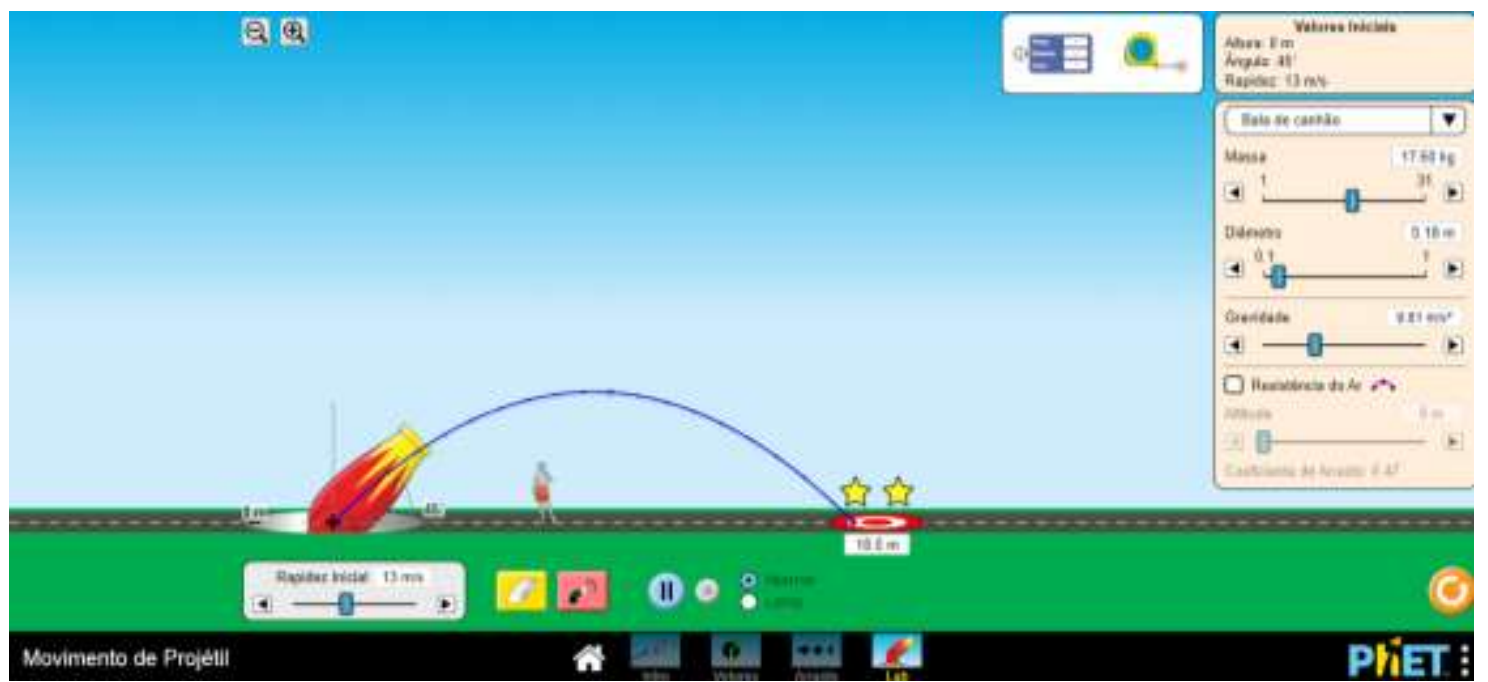

Em seguida, utilizou-se quatro exemplos práticos para a aplicação dessa equação. Sendo, o primeiro exemplo: "Marcos se encontra em um lado do rio, enquanto Paulo está do outro lado, ambos a uma distância de 10 metros um do outro. Marcos decide jogar uma bola para Paulo, na jogada a bola atingiu um ângulo de 60 graus. Considere a gravidade igual a 9,81. Qual a velocidade atingida pela bola quando foi jogada por marcos para chegar em Pedro? ".

Segundo exemplo: "Nara estava a jogar ping-pong com a sua amiga. Ao arremessar a bola para o lado da adversária que estava a 15 metros de distância, a bola atingiu uma 
velocidade, determinada pelo ângulo de 30 graus. Considere a gravidade igual a 9,81 metros. Determine a velocidade atingida pela bola ao ser arremessada por Nara".

Terceiro exemplo: "Ao ser lançado a bola do canhão formando um ângulo de 45 graus, a uma distância de 18 metros do alvo, com gravidade igual a 9,81. Determine a velocidade que a bola de canhão deve atingir para conseguir chegar ao alvo. ".

Quarto exemplo: “Ao ser lançado a bola do canhão formando um ângulo de 70 graus, a uma distância de 10 metros do alvo, com gravidade igual a 9,81. Determine a velocidade que a bola de canhão deve atingir para conseguir chegar ao alvo".

Além dos exemplos citados acima, os alunos compreenderam que na prática o alcance máximo é dado quando o ângulo é $45^{\circ}$, percebido pela equação e no simulador, mostrando um conhecimento prévio para o próximo conteúdo que é as relações trigonométricas como funções trigonométricas. Fato também observado por Maceti, Levada e Lautenschleguer (2012) que, para ser obtido o alcance máximo horizontal, é necessário lançar o projétil com $45^{\circ}$. Para uma velocidade pré-determinada, esta é a direção de lançamento que gera o maior alcance.

Durante toda a resolução e aplicação de cada questão aconteceram muitas interações dos discentes, pois queriam responderem as questões, simular nos seus smartphones ou computadores. Cada exemplo era resolvido de forma escrita, utilizando a equação de Lançamento de Projéteis e logo após, era aplicado estas informações no simulador, e assim ocorria a visualização do lançamento, compreendendo uma relação de teoria e prática de forma interativa e participativa. Essa interação também havia sido percebida por Feitosa e Lavor (2020) ao trabalhar com a plataforma PhET no ensino de circuitos elétricos, em que concluíram que que as simulações causam motivações aos discentes, que se impressionam e tendem a apresentar melhores resultados de aprendizagem.

A avaliação foi compreendida de uma atividade que apresentava quatro questões contextualizadas. A primeira questão colocou uma situação hipotética, em que um jogador de futebol precisaria pagar uma falta, e para isso a bola, ao ser chutada, deveria ser arremessada acima da barreira de jogadores, para chegar ao gol. Na questão foram informadas a inclinação em que a bola se encontrava quando o jogador chutou, a distância até a trave e a gravidade (valor fixado no simulador), sendo assim, restava que o discente aplicasse essas informações na equação de lançamento de projeteis e encontrasse o valor da velocidade que a bola deveria atingir. Assim, apenas dois estudantes não acertaram completamente a primeira questão. Estes resultados podem ser visualizados pelo gráfico da Figura 4. 
Figura 4: Primeira questão da atividade

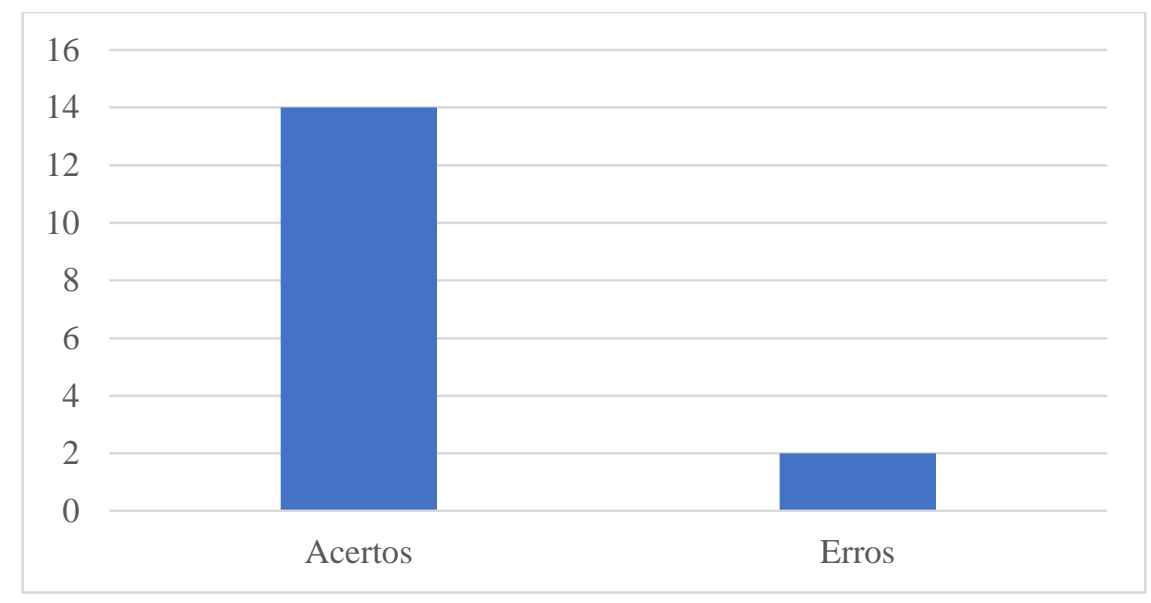

A segunda questão colocou a situação hipotética de um jogador de tênis, em que precisava bater na bolinha para que ela pudesse ser arremessada até chegar no lado adversário, ultrapassando a rede. Os percentuais de acertos podem ser visualizados no gráfico da Figura 5.

Figura 5: Segunda questão da atividade

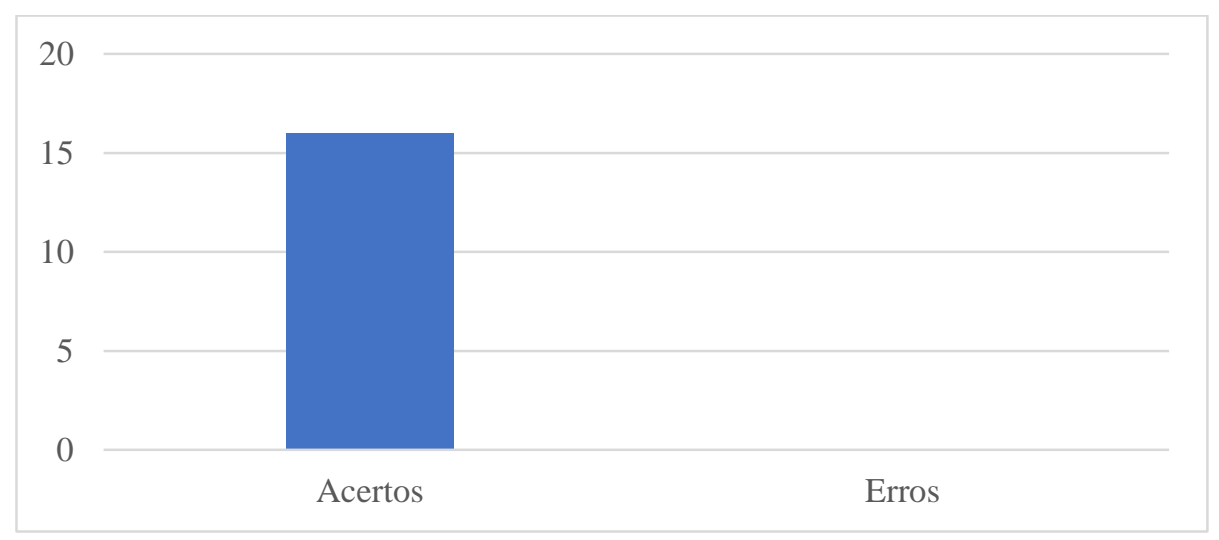

A terceira questão tratava-se de dois grupos que jogavam carimba, assim um dos integrantes que estava com a bola, precisava arremessa-la para que passasse do campo adversário, e chegasse nas mãos do seu componente da equipe, que se encontrava no local "morte" do jogo. Ambas as questões apresentaram a inclinação das bolsas, ao serem arremessadas, como também a distância dos alvos que deveriam chegar, assim o discente precisava calcular a velocidade que ambas as bolas deveriam obter para chegar ao local destinado. Logo, a terceira questão resultou em $100 \%$ de acertos, como mostra o gráfico da Figura 6. 
Figura 6: Terceira questão da atividade

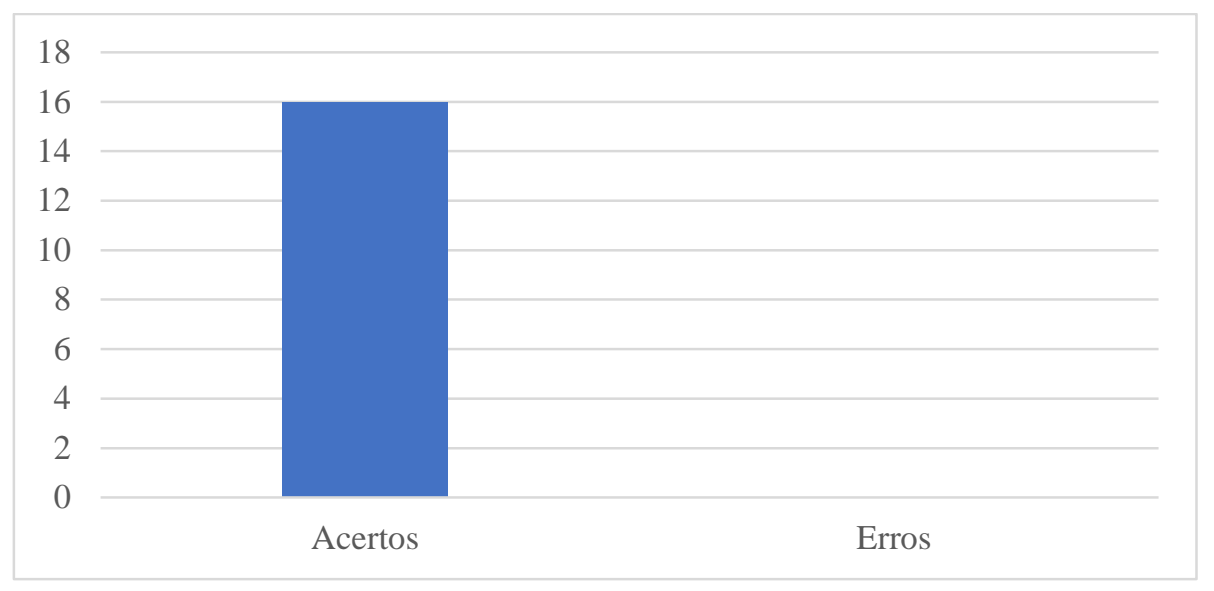

A quarta questão apresentou a situação hipotética de dois estudantes que estavam em uma mesma sala de aula brincando de arremessar bolas de papel, um deles jogou a bola para o outro que estava em uma distância significativa. Na questão foram apresentados a angulação que a bola de papel estava quando foi arremessada e a distância entre os alunos. Assim, deveria ser calculado a velocidade que a bola deveria atingir para que chegasse ao seu destino final. Esta questão apresentou 6,25\% de erros, o que equivale a um estudante e pode ser observado no gráfico da Figura 7.

Figura 7: Quarta questão da atividade

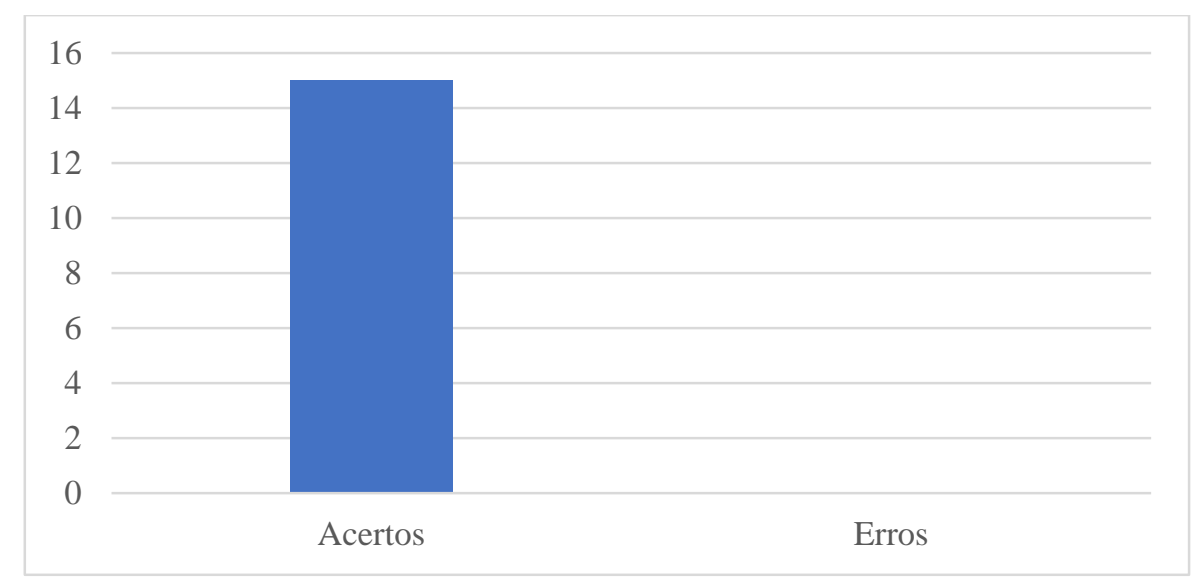

Após isso, os discentes foram convidados a responderem um questionário de satisfação para que os dados coletados pudessem estimular ou não outras atividades da mesma natureza, bem como, utilizar esta metodologia em outras turmas. Na ocasião, 81,3\% dos estudantes aprovaram a aplicação do simulador e a metodologia utilizada e afirmaram ter contribuído para seu ensino e aprendizagem. Quanto a importância da aplicação das tecnologias no ensino de alguns conteúdos, $87,5 \%$ afirmaram, positivamente, a contribuição dessa ferramenta para esse 
processo. Quando perguntado aos discentes se havia participado, em algum dado momento de sua vida acadêmica, de uma aula que envolvessem duas ou mais disciplinas ao mesmo tempo, 93,8\% afirmaram que já havia tido contato com esse método de ensino e que estimula mais a aprendizagem, corroborando com Santos et al. (2019) que afirma que a interdisciplinaridade pode contribuir com a melhoria da aprendizagem de certo conceitos, contribuindo para o desenvolvimento cognitivo de cada discente e proporcionando o entendimento de conceitos das várias áreas do conhecimento.

Os discentes apresentaram de forma escrita alguns critérios que contribuíram para seu processo de aprendizado e que ajudaram a compreender o conteúdo que estava sendo ministrado, sendo algumas de suas falas relatadas como:

Estudante 1: "A mistura que fizeram, e o jogo intuitivo ajudou bastante para compreender melhor o estudo".

Estudante 2: "O simulador, facilitou bastante a aprendizagem do conteúdo explicado". Estudante 3: "O uso do simulador durante a aula, me ajudou a perceber a diferença entre tentativas aleatórias e tentativas calculadas e a importância dos cálculos".

Estudante 4: "O simulador ajudou muito na compreensão".

A BNCC apresenta na secção da área de Matemática e suas tecnologias no ensino médio, que propor jogos ou aplicações possibilita que os discentes construam uma associação integrada da Matemática, na perspectiva de uma aplicação à realidade. Os comentários vêm a corroborar, pois:

\footnotetext{
Para que esses propósitos se concretizem nessa área, os estudantes devem desenvolver habilidades relativas aos processos de investigação, de construção de modelos e de resolução de problemas. Para tanto, eles devem mobilizar seu modo próprio de raciocinar, representar, comunicar, argumentar e, com base em discussões e validações conjuntas, aprender conceitos e desenvolver representações e procedimentos cada vez mais sofisticados (BNCC, p. 529).
}

Dessa forma, os dados refletem que os discentes compreenderam o conteúdo exposto e ainda conseguiram relacioná-lo na aplicação do simulador, resultando em um conhecimento que se refere a teoria e prática, resultante da resolução escrita através da equação do lançamento de projéteis e a aplicação dessas informações no simulador, e além disso os estudantes conseguiram tirar informações das questões contextualizadas e transformá-las em dado, de forma que a aula se tornou interativa e interdisciplinar contando com a motivação e interação dos mesmos. 


\section{CONSIDERAÇÕES}

Este trabalho apresentou uma sequência de ensino investigativa no estudo interdisciplinar de trigonometria aplicada ao lançamento de projéteis. Nas etapas, além de apresentação de aplicações e demonstrações, foi utilizado um simulador da plataforma PhET.

Os resultados apontam que a utilização da plataforma PhET para o estudo interdisciplinar da Trigonometria com o Lançamento de Projéteis foi uma metodologia que proporcionou a visualização de forma prática do conteúdo ministrado durante a aula, em que foram trabalhados a trigonometria fazendo conexões com a Física e a própria Matemática.

Portanto, as tecnológicas educativas favorecem para o ensino e aprendizado por meio da demonstração prática dos conteúdos envolvidos, desde que sejam aliados a um planejamento estruturado e seguido de uma sequência de ensino. Assim, espera-se que esse trabalho cause uma reflexão em torno do ensino de matemática de forma interdisciplinar mediado pelas tecnologias de ensino que possam causar motivação e compreensão no ensino e aprendizagem.

\section{REFERÊNCIAS}

AZEVÊDO, Lidiany Bezerra Silva de. FIREMAN, Elton Casado. Sequência de ensino investigativa: problematizando aulas de ciências nos anos iniciais com conteúdo de eletricidade. REnCiMa, v.8, n.2, p.143-161, 2017. Disponível em:

http://revistapos.cruzeirodosul.edu.br/index.php/rencima/article/view/1223. Acesso em: 02 jul. 2020.

BELLUCCO, Alex. Uma proposta de sequência de ensino investigativa sobre quantidade de movimento, sua conservação e as leis de Newton. Cad. Bras. Ens. Fís., v. 31, n. 1, p. 30-59, abr. 2014. Disponível em: https://dialnet.unirioja.es/servlet/articulo?codigo=5165601. Acesso em: 10 jun. 2020.

BRITO, Robson Souto; MOITA, Filomena Maria Gonçalves da Silva Cordeiro; LOPES, Maria da Conceição. ROBÓTICA EDUCACIONAL: desafios e possibilidades no trabalho interdisciplinar entre matemática e física: educational robotics: challenges and possibilities in the interdisciplinary work between mathematics and physics. Ensino da Matemática em Debate, São Paulo, v. 5, n. 1, p. 27-44, 2018. Disponível em: http://200.144.145.24/emd/article/view/36687. Acesso em: 22 jun. 2020.

CARVALHO, Anna Maria Pessoa de. O ENSINO DE CIÊNCIAS E A PROPOSIÇÃO DE SEQUÊNCIAS DE ENSINO INVESTIGATIVAS, 2013. 15 p. Disponível em: https://edisciplinas.usp.br/pluginfile.php/4300055/mod_resource/content/1/O\%20ensino\%20d e\%20ciencias\%20e\%20a\%20proposicao\%20de\%20sequencias.pdf. Acesso em 23 jun. 2020.

CAVALCANTE, Artur Araújo; SALES, Gilvandenys Leite. AS CONTRIBUIÇÕES DAS SIMULAÇÕES FORCES AND MOTION: basics (html5) e projectile motion (html5), da plataforma phet, para o ensino da mecânica Newtoniana. Revista Exitus, Santarém/pa, v. 10, 
p. 1-27, 2020. Disponível em:

http://www.ufopa.edu.br/portaldeperiodicos/index.php/revistaexitus/article/view/1142. Acesso em: 20 jun. 2020.

CONSELHO NACIONAL DE EDUCAÇÃO. BNCC: Base Nacional Comum Curricular. Brasil: BR, 2018. Disponível em:

http://basenacionalcomum.mec.gov.br/images/BNCC_EI_EF_110518_versaofinal_site.pdf. Acesso em: 26 jun. 2020.

CORREA, Diego Rafael Nespeque. Uma proposta interdisciplinar para o ensino de Física, Química e Biologia através do estudo de biomateriais. Revista Iluminart, São Paulo, v. 17, n. 17, p. 81-91, dez. 2019. V.17. Disponível em:

http://revistailuminart.ti.srt.ifsp.edu.br/index.php/iluminart/article/view/376. Acesso em: 25 maio 2020.

DALAROSA, Adair Angelo. EPISTEMOLOGIA E EDUCAÇÃO: ARTICULAÇÕES CONCEITUAIS: epistemologyand education: conceptualarticulations. Uepg Ci. Hum. Ci Soc. Apl. Ling., Letras e Artes, Ponta Grossa, p. 343-350, dez. 2008. Disponível em: https://revistas.apps.uepg.br/index.php/sociais/article/view/2860. Acesso em: 25 maio 2020.

DIONIZIO, Fátima Queiroz. BRANDT, Célia Finck. Análise das dificuldades apresentadas pelos alunos do ensino médio em trigonometria. X Congresso Nacional de Educação EDUCERE. Curitiba, 2011. Disponível em:

https://educere.bruc.com.br/CD2011/pdf/4728_2885.pdf. Acesso em: 02 jul. 2020.

FRANCO, Maria Amélia do Rosário Santoro. Pedagogia e prática docente. São Paulo: Cortez, 2012. 111 p. Disponível em: https://www.escavador.com/sobre/578411/maria-ameliado-rosario-santoro-franco. Acesso em: 05 jun. 2020.

FEITOSA, M., DE AQUINO, A., \& LAVOR, O. ENSINO DE RETAS E PLANOS COM AUXÍLIO DO SOFTWARE GEOGEBRA 3D MOBILE. Reamec: Rede Amazônica de Educação em Ciências e Matemática, 2020. Disponível em: http://periodicoscientificos.ufmt.br/ojs/index.php/reamec/article/view/10042. Acesso em: 03 jul. 2020.

FEITOSA, M. \& Lavor, O. ENSINO DE CIRCUITOS ELÉTRICOS COM AUXÍLIO DE UM SIMULADOR DO PHET. Reamec: Rede Amazônica de Educação em Ciências e Matemática, p. 125-138, 2020. Disponível:

http://periodicoscientificos.ufmt.br/ojs/index.php/reamec/article/view/9014. Acesso em: 03 jul. 2020.

GONÇALVES, Harryson Júnio Lessa; BONI, Bianca Rafaela; GOMES, Ana Clédina Rodrigues. Currículo interdisciplinar no ensino integral: concepções de professores paulistas de Ciências da Natureza e Matemática. Revista Eletrônica de Educação: Conceptions of integral school and interdisciplinary curriculum, São Carlos, v. 13, n. 2, p. 646-658, maio 2019. Disponível em: http://www.reveduc.ufscar.br/index.php/reveduc/article/view/2386. Acesso em: 20 maio 2020.

\section{LIMA, Vania Moreira. UMA SEQUÊNCIA DE ENSINO INVESTIGATIVA EM AULAS DE CIÊNCIAS DO $9^{\circ}$ ANO DE UMA ESCOLA PÚBLICA: REFLEXÕES E}


APONTAMENTOS SOBRE O APRENDIZADO DE CONCEITOS,

PROCEDIMENTOS E ATITUDES. 2015. 23 f. Dissertação (Doutorado) - Curso de

Programa de Mestrado Profissional em Ensino de Ciências do Instituto de Ciências Exatas e Biológicas, Universidade Federal de Ouro Preto, Ouro Preto, 2015. Disponível em: https://repositorio.ufop.br/handle/123456789/5681. Acesso em: 28 maio 2020.

LOPES, Maria Maroni. Contribuições do software GeoGebra no ensino e aprendizagem de trigonometria. Xiii Ciaem, Recife, 2011. Disponível em:

http://www.educadores.diaadia.pr.gov.br/arquivos/File/dezembro2013/matematica_artigos/art igo_maria_maroni_lopes.pdf. Acesso em: 25 jun. 2020.

LOUREIRO, Luiz Francisco; NASCIMENTO, Ana Claudeise Silva do; SILVEIRA, Cristiane da; SOUSA, Marilia de Jesus da Silva e; COSTA, Veronica Prudente.

INTERDISCIPLINARIDADE: UMA PROPOSTA EPISTEMOLÓGICA PARA A CIÊNCIA PÓS-MODERNA: interdisciplinarity: an epistemological proposal for postmodern science. Interscienceplace, v. 14, n. 4, p. 127-240, out. 2019. Disponível em: http://www.interscienceplace.org/isp/index.php/isp/article/view/873. Acesso em: 22 maio 2020.

MACETI, Huemerson; LEVADA, Celso Luis; LAUTENSCHLEGUER, Ivan José. CONSIDERAÇÕES SOBRE O ALCANCE NO LANÇAMENTO OBLÍQUO. Caderno de física da UEFS 10, p. 7 - 17, 2012. Disponível em https://www.academia.edu/download/35203289/a1LevadaLobliquo.pdf. Acesso em: 04 jul. 2020.

MOURA, Fábio Andrade de; SILVA, Rubens. SEQUÊNCIA DE ENSINO INVESTIGATIVA PARA O ESTUDO DO EMPUXO NO ENSINO MÉDIO: sequence of investigative teaching for the study of buoyancy in high school. Reppe: Revista do

Programa de Pós-graduação em Ensino, Cornélio Procópio, v. 3, n. 1, p. 38-61, 2019. Disponível em: http://seer.uenp.edu.br/index.php/reppe/article/view/1509. Acesso em: 10 jun. 2020.

NASCIMENTO, Stephany Siqueira Barbosa. SEQUÊNCIA DE ENSINO INVESTIGATIVO “ONDE ESTÁ O AR?”. Jataí: Produto Educacional, 2016. Disponível em: https://repositorio.ifg.edu.br/handle/prefix/411. Acesso em: 02 jun. 2020.

NUNES, M. S; FERREIRA, F. C. L; DE OLIVEIRA, M. R. D.; PASCHOAL, C. M. M. Uma análise sobre experiências docentes no ensino de física em escolas públicas no Brasil e no Timor-Leste. M.S. Nunes et al., Scientia Plena, Pará, vol. 15, num. 7 ,2019. Disponível em: https://www_scientiaplena_org_br-timbrasil.br.overbrowser.com/sp/article/view/4888. Acesso em: 20 jun. 2020.

OLIVEIRA, Francisco Canindé de. Dificuldades no processo ensino aprendizagem de Trigonometria por meio de atividades. 2006. 74 f. Dissertação (Mestrado) - Curso de Ciências Exatas e da Terra, Universidade Federal do Rio Grande do Norte, Natal, 2006. Disponível em: https://repositorio.ufrn.br/jspui/handle/123456789/16022. Acesso em: 25 jun. 2020.

OLIVEIRA, Gerson Pastre de; FERNANDES, Ricardo Uchoa. O uso de tecnologias para ensino de trigonometria: estratégias pedagógicas para a construção significativa da 
aprendizagem: the use of technologies to teach trigonometry: teaching strategies for meaningful learning construction. 2010. Educ. Matem. Pesq, São Paulo, v. 12, n. 3, p. 548577. Disponível em: https://revistas.pucsp.br/emp/article/view/4631. Acesso em: 20 maio 2020.

REILS Francenildo Baia; SILVA, Josiane Reis; SÁ, Leuzilda Rodrigues. GEOMETRIA PLANA E DEFICIÊNCIA VISUAL: UMA PROPOSTA DE ENSINO SOBRE AS CARACTERÍSTICAS DO TRIÂNGULO RETÂNGULO UTILIZANDO MIRITI. Encontro Nacional de Educação Matemática, Cuiabá, jun. 2019. Disponível em: https://www.sbemmatogrosso.com.br/eventos/index.php/enem/2019/paper/viewPaper/2697. Acesso em: 12 maio 2020.

SANTOS, Antônio Vanderlei dos; FONTANA, Rosane; RODRIGUES, Juliana; MEGGIOLAR, Graciela Paz. UMA APLICAÇÃO DE CAMPOS CONCEITUAIS NO ENSINO INTERDISCIPLINAR DE ASTRONOMIA NA FÍSICA E NA MATEMÁTICA NO ENSINO MÉDIO: an applicationfieldsofconceptualteachingofastronomyininterdisciplinaryphysicsandmathematicsi nsecondary education. Areté, Manaus, v. 12, n. 26, p. 183-198, ago. 2019. Disponível em: http://periodicos.uea.edu.br/index.php/arete/article/view/1674. Acesso em: 14 jun. 2020.

SANTOS, Boaventura de Sousa. Um discurso sobre as ciências. 5. ed. São Paulo: Cortez, 2008. 92 p. Disponível em: https://www.revistas.ufg.br/interacao/article/view/18405. Acesso em: 10 jun. 2020.

SANTOS, Roziane Aguiar dos. O desenvolvimento de Sequências de Ensino Investigativas como forma de promover a Alfabetização Científica dos alunos dos Anos Iniciais do Ensino Fundamental. 2016. 157 f. Dissertação (Doutorado) - Curso de Programa de Pósgraduação em Formação de Professores da Educação Básica (ppge), Universidade Estadual de Santa Cruz (uesc-ba), Ilhéus, 2016. Disponível em: http://www.biblioteca.uesc.br/biblioteca/bdtd/201420650D.pdf. Acesso em: 11 jun. 2020.

SOUZA, Mariana Aranha de. FAZENDA, Ivani Catarina Arantes. Interdisciplinaridade, currículo e tecnologia: um estudo sobre práticas pedagógicas no ensino fundamental. RIAEE - Revista Ibero-Americana de Estudos em Educação, v. 12, n. 2, p. 708-721, 2017. Disponível em: https://periodicos.fclar.unesp.br/iberoamericana/article/view/8303. Acesso em: 22 jun. 2020.

ZARA, Reginaldo A.. Reflexão sobre a eficácia do uso de um ambiente virtual no ensino de Física. II Enined - Encontro Nacional de Informática e Educação, Cascavel, p. 265-272, 2011. Disponível em: https://www.academia.edu/download/30235824/a29.pdf. Acesso em: 22 jun. 2020.

Submetido em: 06 de julho de 2020.

Aprovado em: 19 de agosto de 2020. 